JOURNAL DE PHYSIQUE IV

Colloque C7, supplément au Journal de Physique III, Vol. 1, décembre 1991

C $7-591$

\title{
AN INTERACTION BETWEEN THE REPETITIVELY PULSED XeCl LASER RADIATION AND METALS
}

V.M. BORISOV, A.M. KOVALEVICH and Yu.Yu. STEPANOV

The Troitsk Kurchatov Research Institute, Moscow Region, Troitsk 142092, USSR

Results are described of experiments and a theoretical analysis of the processes of interaction between the exc1mer radiation w1th the intensity of $\sim 1 \mathrm{GW} / \mathrm{cm}^{2}$ and a metal surface.The dynamics has been investigated of the formation, heating and expansion of the plasma in the vicinity of the surface under the atmospher1c pressure. The spectroscop1c measurements of the luminescence from the metal vapor made it possible to determine pressure, temperature and concentration of the plasma.

An exposure of metals to the repetilively pulsed $\mathrm{XeCl}_{\mathrm{l}}$ laser radiation with the intensity of $10^{6}-10^{8} \mathrm{~W} / \mathrm{cm}^{2}$ was studied experimentally and calculated. The main channels of energy losses have been elucidated which are assoclated with metal evaporation, heat radiation and convect1re cooling by an amblent gas. An existence is shown of optimal conditions for heating of metal samples which depend on the laser radiation intensity. The optimal conditions for each of the metals under study are governed by its optical and thermophysical properties.

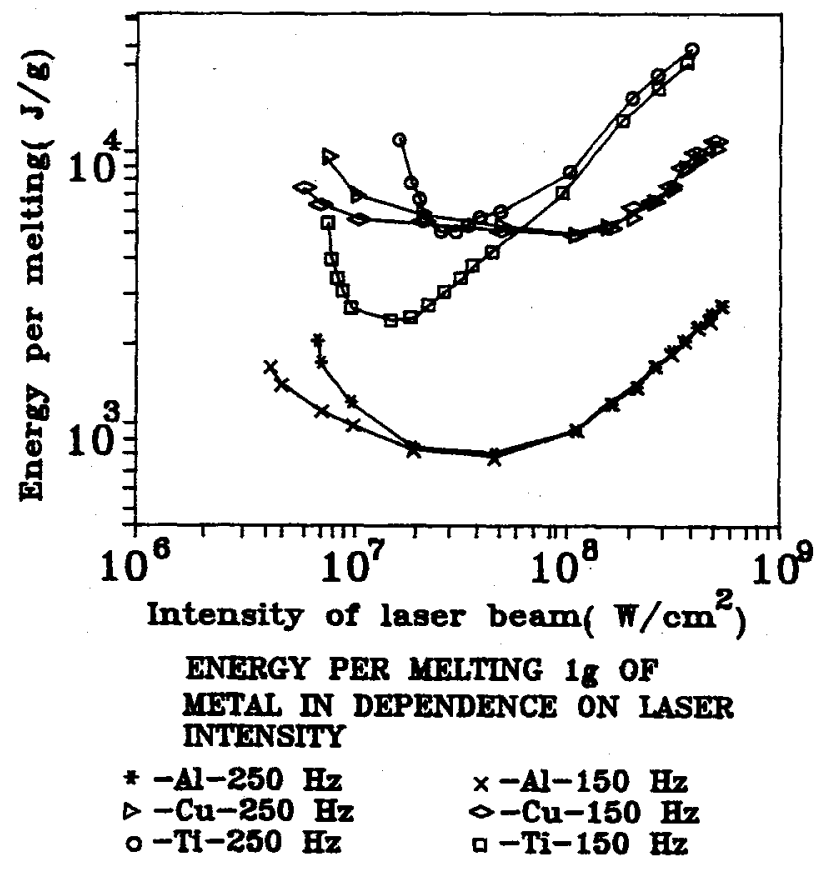

